\title{
Serum ferritin is a candidate biomarker of disease aggravation in amyotrophic lateral sclerosis
}

\author{
JIXU YU ${ }^{1,2}$, NIAN WANG ${ }^{1}$, FAYING QI $^{1}$, XIANJUN WANG ${ }^{1}$, QIYI ZHU ${ }^{1}$, YUCHENG LU ${ }^{2}$, \\ HUILING ZHANG ${ }^{3}$, FENGYUAN CHE ${ }^{1,2}$ and WEI LI ${ }^{1}$ \\ ${ }^{1}$ Department of Neurology; ${ }^{2}$ Central Laboratory; ${ }^{3}$ Clinical Laboratory, \\ Linyi People's Hospital, Linyi, Shandong 276003, P.R. China
}

Received March 16, 2018; Accepted July 23, 2018

DOI: $10.3892 /$ br.2018.1138

\begin{abstract}
Amyotrophic lateral sclerosis (ALS) is a neurodegenerative disease. The mechanism that defines the loss of neurons in ALS is still not clearly understood, and there is no effective therapy to block its progression. Previous studies indicate that a disorder of iron homeostasis exists in ALS and based on this, the change of serum iron and ferritin and the association between iron metabolism and clinical features in Chinese Han patients with ALS was further investigated in the present study, in order to define its pathogenesis. Two cohorts were established: An ALS group consisting of 24 patients and a control group consisting of 38 healthy volunteers. Venous blood samples were collected for serum iron and ferritin analysis. The results indicated that the levels of serum iron were significantly decreased in patients with ALS $(\mathrm{P}<0.05)$, while there was no significant difference in serum ferritin between the ALS and control groups. However, the levels of serum ferritin were increased significantly in ALS patients with bulbar-onset (vs. limb-onset in females), dysphagia (vs. without dysphagia), longer disease duration (>12 months vs. $\leq 12$ months in males) and lower ALS Functional Rating Scale-Revised score ( $<33$ vs. $\geq 33$; $\mathrm{P}<0.05$ ). These results suggested that there was dysregulation of iron metabolism in Chinese Han patients with ALS and that serum ferritin may be a candidate biomarker of aggravation in these patients.
\end{abstract}

\section{Introduction}

Amyotrophic lateral sclerosis (ALS) is a progressive, lethal disease characterized by degeneration of motor neurons in

Correspondence to: Professor Wei Li or Dr Jixu Yu, Department of Neurology, Linyi People's Hospital, 27 Jie Fang Road, Linyi, Shandong 276003, P.R. China

E-mail: liweidoc@163.com

E-mail:yujixu@yahoo.com

Key words: amyotrophic lateral sclerosis, neurodegenerative disease, iron, serum iron, serum ferritin the cortex, brainstem and spinal cord $(1,2)$. ALS is among the most common types of neurodegenerative disorder, with an incidence of approximately 2-3/100,000 individuals in Europe $(3,4)$. The majority of cases of ALS are sporadic, while $5-10 \%$ are familial $(5,6)$. With the current therapy (riluzole, $100 \mathrm{mg} /$ day), the typical survival time for patients is $3-5$ years following diagnosis (7).

Previous studies have indicated that the loss of neurons in ALS results from a complex interplay among oxidative injury, excitotoxic stimulation, aggregation and/or dysfunction of critical proteins, and genetic factors (8-12). However, to the best of our knowledge, the mechanism that defines the loss of neurons in ALS is not clearly understood. Further studies have demonstrated the following: A disorder of iron homeostasis exists in ALS (13-17); there is increased iron in the spinal cord of patients with ALS $(18,19)$; the iron level in the cerebrospinal fluid of patients with ALS was higher than in control subjects $(20,21)$; and serum ferritin levels were increased in patients with ALS (22-26). However, it remains unconfirmed whether a high level of ferritin is specific to ALS. A number of studies have reported that patients with elevated serum ferritin have a shorter survival time (25); however, another study concluded that ferritin levels are unrelated to the survival of patients with ALS (26).

In the present study, the levels of serum iron and ferritin in Chinese Han patients with ALS and control subjects were measured, and the association between iron metabolism and clinical features was studied in order to implicate iron metabolism in Chinese Han patients with ALS.

\section{Materials and methods}

Subjects. Two cohorts were established as follows: An ALS group consisting of 24 patients, 14 males and 10 females (42-69 years old; mean, 51.96 \pm 7.57 years), all diagnosed with ALS according to El Escorial criteria (27); and a control group consisting of 38 healthy volunteers, 28 males and 10 females (50-62 years old; mean, 53.32 \pm 3.28 years), recruited from the local community. Participants who had iron deficiency anemia, acute inflammation, a history of chronic kidney disease, neurologic or psychiatric diseases, or neurologic sequelae induced by brain trauma were excluded. All subjects were of Chinese Han ethnicity. All blood samples were collected for analysis 
of serum iron and ferritin, and then serum iron and ferritin was compared between those patients with limb-onset and bulbar-onset, with dysphagia and without dysphagia, disease duration $\leq 12$ months and $>12$ months, and ALS Functional Rating Scale-Revised (ALSFRS-R) score $<33$ points and $\geq 33$ points. The ALSFRS-R is among the most frequently used scales in the neurological and functional assessment of patients with ALS, and survival time is reportedly shorter in ALS patients with lower ALSFRS-R scores (28). The range of ALSFRS-R scores was 20-42 with a mean $33.04 \pm 6.89$ in the present study, and therefore patients with an ALSFRS-R score $<33$ points were separated from those with a score $\geq 33$ points for analysis, as in previous studies $(28,29)$.

Each subject that agreed to enroll in the study reviewed and signed an informed consent form prior to their participation. The study protocol and consent forms were approved by the Medical Ethics Committee of Linyi People's Hospital, Linyi, China.

Measurement of serum iron. Venous blood samples $(5 \mathrm{ml})$ were collected at Linyi People's Hospital (Linyi, China) between 2014 and 2016, and placed upright for $2 \mathrm{~h}$ for clotting at room temperature. Then, the samples were centrifuged at $3,000 \mathrm{x} g$ for $15 \mathrm{~min}$, and the supernatant serum was collected for analysis of serum iron and ferritin. Subjects did not have a fever or other signs of inflammation when the blood samples were taken. Iron reagent kit (catalogue no. 467910) was purchased from Beckman Coulter, Inc. and the iron assays were performed on a UniCel DxC 800 Synchron Clinical System (both from Beckman Coulter, Inc., Brea, CA, USA). Iron concentration was measured by an end-point method. In brief, iron is released from transferrin by decomposition of acetic acid and then reduced to ferrous ion by hydroxylamine and sulfhydryl acetate, which combines with zinc-iron by complexation. The proper quantities of samples and reagents were automatically distributed in proportion to a reaction cup by the Synchron System. The proportion of samples to reagents was 1:8. The absorbance at $560 \mathrm{~nm}$ was then measured; the change of this absorption is directly proportional to the iron concentration of the samples. Subsequently, the system calculated the iron concentration. All tests were conducted according to the manufacturer's instructions and the standard operating procedures at the Biochemistry Department of Linyi People's Hospital. The reference range of serum iron was 8.1-32.6 $\mu \mathrm{mol} / 1$.

Measurement of serum ferritin. Ferritin detection kit (catalogue no.: 04491785) was purchased from Roche Diagnostics GmbH (Mannheim, Germany). Ferritin was measured on a Roche Cobas E601 Immunology analyzer (Roche Diagnostics $\mathrm{GmbH})$. Serum samples $(10 \mu \mathrm{l})$ were reacted with the biotin monoclonal specific antibody of ferritin, and the specific monoclonal antibody of ferritin was tagged with the ruthenium complex to form sandwich complexes. Following the addition of particles coated with streptavidin, the complexes combined with them to form a solid phase through interaction between biotin and streptavidin. The reaction mixture was placed in a measuring cell, and particles were adsorbed onto the surface of the electrode by magnetism. Procell/Procell M (catalogue no. 04880340190; Roche Diagnostics GmbH) was used to remove the uncombined substances. Chemiluminescence was produced by applying voltage to the electrode, which was then measured by a photomultiplier. Results were calculated using a calibration curve, which was produced by a two-point calibration and master curve (provided by the reagent barcode). All tests were conducted according to the manufacturer's instructions and standard operating procedures at the Immunology Department of Linyi People's Hospital. The reference ranges of serum ferritin were as follows: $30-400 \mathrm{ng} / \mathrm{ml}$ for males and $13-150 \mathrm{ng} / \mathrm{ml}$ for females.

Statistical analysis. Results are expressed as the mean \pm standard deviation. Statistical analyses were performed using the unpaired t-test and Wilcoxon rank-sum test, depending on the normality of the data. The rank-sum test was used when comparing serum ferritin between male control and ALS patients, and the unpaired Student's t-test was used to analyze all other datasets. Difference was considered to be significant at $\mathrm{P}<0.05$. Statistical analysis was performed using the SAS System for Windows v8 (SAS Institute Inc., Cary, NC, USA).

\section{Results}

Patient characteristics. The patients with ALS in the current study included 10 definite ALS and 14 probable ALS diagnoses. A total of 16 patients exhibited signs of limb-onset ALS and 8 patients signs of bulbar-onset ALS. Dysphagia symptoms were apparent in 17 patients $(71 \%)$ when collecting blood samples. All patients had sporadic ALS. Table I presents the clinical characteristics of the included patients. No significant difference in age was identified between the ALS patients and control subjects $(\mathrm{P}=0.4129)$.

Serum iron and ferritin in patients with ALS and the control group. As illustrated in Table II, the serum iron of the ALS group was significantly lower than that of the control group $(\mathrm{P}=0.0074)$, while there was no significant difference in serum ferritin between the groups (male, $\mathrm{P}=0.3504$; female, $\mathrm{P}=0.1068$; Table III). However, the mean levels of serum ferritin in the ALS group were higher than those in the control group for both male and female patients; therefore, it was indicated that serum ferritin was increased in patients with ALS.

Serum iron and ferritin in patients with limb-onset and bulbaronset ALS. When comparing the serum iron and ferritin levels between patients with limb-onset and bulbar-onset ALS, no significant difference in serum iron was identified $(\mathrm{P}=0.0586$; Table IV). There was also no significant difference in the levels of serum ferritin between male patients with limbonset and bulbar-onset ALS ( $\mathrm{P}=0.2257$; Table V); however, the serum ferritin levels of female patients with bulbar-onset ALS were significantly higher than those of female patients with limb-onset ALS ( $\mathrm{P}=0.008$; Table VI).

Serum iron and ferritin in ALS patients with and without dysphagia. On comparing the serum iron and ferritin between ALS patients with and without dysphagia, no significant difference in serum iron was observed ( $\mathrm{P}=0.7659$; Table IV). 
Table I. Clinical characteristics of included ALS patients.

\begin{tabular}{|c|c|c|c|c|c|c|}
\hline Patient & Sex & Age, years & Diagnosis & Onset site & Disease duration, months & ALSFRS-R score \\
\hline 1 & Male & 52 & Definite & Bulbar-onset & 36 & 25 \\
\hline 2 & Male & 47 & Probable & Limb-onset & 12 & 37 \\
\hline 3 & Male & 69 & Probable & Limb-onset & 30 & 23 \\
\hline 4 & Male & 45 & Definite & Limb-onset & 24 & 31 \\
\hline 5 & Male & 50 & Probable & Bulbar-onset & 16 & 39 \\
\hline 6 & Male & 42 & Probable & Limb-onset & 24 & 22 \\
\hline 7 & Male & 47 & Probable & Limb-onset & 24 & 35 \\
\hline 8 & Male & 62 & Definite & Limb-onset & 12 & 41 \\
\hline 9 & Male & 48 & Definite & Limb-onset & 18 & 40 \\
\hline 10 & Male & 55 & Probable & Limb-onset & 12 & 36 \\
\hline 11 & Male & 48 & Probable & Limb-onset & 24 & 36 \\
\hline 12 & Male & 43 & Probable & Limb-onset & 7 & 42 \\
\hline 13 & Male & 52 & Probable & Bulbar-onset & 6 & 37 \\
\hline 14 & Male & 68 & Definite & Bulbar-onset & 12 & 39 \\
\hline 15 & Female & 48 & Probable & Limb-onset & 30 & 31 \\
\hline 16 & Female & 64 & Definite & Limb-onset & 10 & 20 \\
\hline 17 & Female & 46 & Definite & Limb-onset & 12 & 25 \\
\hline 18 & Female & 49 & Probable & Bulbar-onset & 30 & 22 \\
\hline 19 & Female & 46 & Definite & Bulbar-onset & 24 & 30 \\
\hline 20 & Female & 53 & Definite & Bulbar-onset & 24 & 31 \\
\hline 21 & Female & 56 & Probable & Limb-onset & 28 & 35 \\
\hline 22 & Female & 45 & Probable & Limb-onset & 12 & 36 \\
\hline 23 & Female & 54 & Probable & Bulbar-onset & 12 & 39 \\
\hline 24 & Female & 58 & Definite & Limb-onset & 17 & 41 \\
\hline
\end{tabular}

ALS, amyotrophic lateral sclerosis; ALSFRS-R, Amyotrophic Lateral Sclerosis Functional Rating Scale-Revised.

Table II. Serum iron of ALS patients and controls.

\begin{tabular}{lccc}
\hline Group & $\begin{array}{c}\text { Number of } \\
\text { subjects }\end{array}$ & $\begin{array}{c}\text { Serum iron } \\
\mu \mathrm{mol} / \mathrm{l}\end{array}$ & P-value \\
\hline Control & 38 & $19.44 \pm 6.47$ & 0.0074 \\
ALS patients & 24 & $14.95 \pm 5.77$ & \\
\hline
\end{tabular}

ALS, amyotrophic lateral sclerosis.

However, the serum ferritin of ALS patients with dysphagia was significantly higher than in those without dysphagia (male, $\mathrm{P}=0.0195$; female, $\mathrm{P}=0.0357$; Tables $\mathrm{V}$ and VI).

Serum iron and ferritin in patients with ALS of different disease duration. The serum iron and ferritin in patients with ALS of different disease durations ( $\leq 12$ months and $>12$ months) were subsequently compared. No significant difference in serum iron in ALS cases of different disease duration was determined ( $\mathrm{P}=0.3852$; Table IV). Serum ferritin was increased significantly in male ALS cases with longer disease duration $(\mathrm{P}=0.0422$; Table $\mathrm{V})$; however, there was no significant difference in serum ferritin in female cases of ALS of different disease duration $(\mathrm{P}=0.2739$; Table $\mathrm{VI})$.
Table III. Serum ferritin of ALS patients and controls.

\begin{tabular}{lccc}
\hline Group & $\begin{array}{c}\text { Number of } \\
\text { subjects }\end{array}$ & $\begin{array}{c}\text { Serum ferritin, } \\
\mathrm{ng} / \mathrm{ml}\end{array}$ & P-value \\
\hline Male control & 28 & $171.35 \pm 73.64$ & 0.3504 \\
Male ALS patients & 14 & $221.95 \pm 138.20$ & \\
Female control & 10 & $93.67 \pm 65.88$ & 0.1068 \\
Female ALS patients & 10 & $157.86 \pm 99.76$ & \\
\hline
\end{tabular}

ALS, amyotrophic lateral sclerosis.

Serum iron and ferritin in ALS patients with different ALSFRS-R scores. By comparing the serum iron and ferritin of ALS patients with different ALSFRS-R scores, it was identified that the levels of serum iron in ALS patients with ALSFRS-R scores $<33$ points were lower compared with in those patients with ALSFRS-R scores $\geq 33$ points $(\mathrm{P}=0.0155$; Table IV). Additionally, the levels of serum ferritin were increased significantly in ALS patients with ALSFRS-R scores $<33$ points compared with in those patients with ALSFRS-R scores $\geq 33$ points (male, $\mathrm{P}=0.0287$; female, $\mathrm{P}=0.0474$, Tables V and VI). 
Table IV. Serum iron of ALS patients.

\begin{tabular}{lccc}
\hline Disease characteristic & Number of subjects & Serum iron, $\mu$ mol/l & P-value \\
\hline Limb-onset & 16 & $13.39 \pm 4.91$ & $18.08 \pm 6.40$ \\
Bulbar-onset & 8 & $14.39 \pm 4.30$ & 0.0586 \\
Without dysphagia & 7 & $15.18 \pm 6.38$ \\
With dysphagia & 17 & $16.40 \pm 8.34$ \\
Disease duration $\leq 12$ months & 10 & $13.91 \pm 2.81$ \\
Disease duration $>12$ months & 14 & $11.69 \pm 4.11$ \\
ALSFRS-R score $<33$ & 10 & $17.28 \pm 5.76$ \\
ALSFRS-R score $\geq 33$ & 14 & 0.7659 \\
\hline
\end{tabular}

ALS, amyotrophic lateral sclerosis; ALSFRS-R, Amyotrophic Lateral Sclerosis Functional Rating Scale-Revised.

Table V. Serum ferritin of male ALS patients.

\begin{tabular}{lccr}
\hline Disease characteristic & Number of subjects & Serum ferritin, ng/ml & P-value \\
\hline Limb-onset & 10 & $251.08 \pm 148.71$ & 0.2257 \\
Bulbar-onset & 4 & $149.12 \pm 80.75$ & 0.0195 \\
Without dysphagia & 4 & $125.68 \pm 33.96$ & 0.0422 \\
With dysphagia & 10 & $260.46 \pm 146.41$ & 0.0287 \\
Disease duration $\leq 12$ months & 6 & $142.46 \pm 58.43$ & \\
Disease duration $>12$ months & 8 & $281.57 \pm 153.47$ & $174.70 \pm 152.14$ \\
ALSFRS-R score $<33$ & 4 & $172.85 \pm 102.45$ & \\
ALSFRS-R score $\geq 33$ & 10 &
\end{tabular}

ALS, amyotrophic lateral sclerosis; ALSFRS-R, Amyotrophic Lateral Sclerosis Functional Rating Scale-Revised.

Table VI. Serum ferritin of female ALS patients.

\begin{tabular}{|c|c|c|c|}
\hline Disease characteristic & Number of subjects & Serum ferritin, $\mathrm{ng} / \mathrm{ml}$ & P-value \\
\hline Limb-onset & 6 & $97.71 \pm 59.42$ & 0.0080 \\
\hline Bulbar-onset & 4 & $248.08 \pm 76.69$ & \\
\hline Without dysphagia & 3 & $61.63 \pm 43.89$ & 0.0357 \\
\hline With dysphagia & 7 & $199.10 \pm 87.59$ & \\
\hline Disease duration $\leq 12$ months & 4 & $113.40 \pm 73.93$ & 0.2739 \\
\hline Disease duration $>12$ months & 6 & $187.50 \pm 109.54$ & \\
\hline ALSFRS-R score $<33$ & 6 & $207.11 \pm 93.09$ & 0.0474 \\
\hline ALSFRS-R score $\geq 33$ & 4 & $83.98 \pm 57.28$ & \\
\hline
\end{tabular}

ALS, amyotrophic lateral sclerosis; ALSFRS-R, Amyotrophic Lateral Sclerosis Functional Rating Scale-Revised.

\section{Discussion}

Iron is established to potentiate the toxic effects of reactive oxygen species by catalyzing the formation of highly reactive hydroxyl radicals from hydrogen peroxide through Fenton chemistry $(30,31)$. Thus, while iron is essential for normal physiology (32), it is also implicated in many pathological processes, including neuron degenerative disorders $(33,34)$.
Iron accelerates $\beta$-amyloid aggregation and promotes oxidative damage in Alzheimer's disease (35-37). A number of studies have indicated that iron is increased in both models of ALS and humans with ALS (38-41). Even though it is unclear whether oxidative stress is a primary or secondary cause of neurodegeneration in ALS, previous study has suggested that it is a major contributory factor that leads to chronic motor neuron death (42). Increased iron levels are possibly involved 
in oxidative damage through the Fenton reaction in ALS, and iron chelation therapy may have potential in the prevention and treatment of ALS $(43,44)$.

Symptoms of dysphagia, difficulty with self-feeding and fatigue with meals often afflict patients with ALS, making them susceptible to a high risk of malnutrition (45). Dysphagia affects up to $80 \%$ of patients with ALS (46), and thus enteral nutrition $(\mathrm{EN})$ and parenteral nutrition $(\mathrm{PN})$ are important for patients with ALS (45). The recommended daily intake of iron for healthy individuals is $10 \mathrm{mg} / \mathrm{day}$, but the iron content of polymeric enteral formulas that are usually employed to meet the nutritional and metabolic needs of patients with ALS ranges from 13 to $24 \mathrm{mg} / 1$ (47). Many patients with ALS receive EN, which may exacerbate iron overload. Although previous studies do not report many patients receiving EN, iron overload exacerbated by EN may serve a role in the reported results (26).

In the present study, no significant difference between the ALS and control subjects was identified regarding serum ferritin, which is in contrast to the results of previous studies (22-26); however, the mean levels of serum ferritin in the ALS group were higher than those in the control group. The levels of serum iron in patients with ALS were significantly lower than those in the control group. The reason for this may be attributed to a number of external factors. Environmental factors, including diet, can affect iron homeostasis in the body. The majority of patients with ALS that were enrolled in the present study lived in their own home and could not get help from health workers, or EN or PN treatment, which could result in malnutrition that further influenced their levels of serum iron. By contrast, the Caucasian patients assessed previously lived in developed countries (26), and likely had greater access to treatments and adequate nutrition compared with patients in the present study, which may explain the significant increase in serum ferritin reported (26). Our previous study indicated that iron levels are increased in the motor cortex of patients with ALS by using susceptibility weighted imaging (48). The majority of the patients with ALS in the present study also participated in our aforementioned previous study. Therefore, it may be concluded that the decrease in serum iron levels does not affect the iron levels of the motor cortex in Chinese Han patients with ALS.

Further investigations were conducted in the present study to clarify the effect of onset site, dysphagia, disease duration and ALSFRS-R scores. The results showed that onset site, dysphagia and disease duration did not affect serum iron in patients with ALS. The levels of serum ferritin were increased significantly in male ALS patients with dysphagia, longer disease duration ( $>12$ months) and lower ALSFRS-R scores ( $<33$ points). Furthermore, the levels of serum ferritin were increased significantly in female ALS patients with bulbaronset, dysphagia and lower ALSFRS-R scores. Intracellular ferritin may be upregulated in response to oxidative stress, and serum ferritin may be increased in patients with ALS due to oxidative stress (25). The results of the present study indicate that serum ferritin is a marker of aggravation in ALS. However, a limitation of this study was the relatively small sample group, and thus data from more patients should be collected for further studies; a further aim is to assess other molecules related to ALS in future study.
In conclusion, serum iron levels of patients with ALS were decreased significantly in the present study, while serum ferritin exhibited an increasing tendency. Furthermore, the levels of serum ferritin were increased significantly in ALS patients with bulbar-onset, dysphagia, longer disease duration and lower ALSFRS-R scores. Collectively the results indicate that dysregulation of iron metabolism exists in Chinese Han patients with ALS, and that serum ferritin may be a candidate biomarker of aggravation in ALS.

\section{Acknowledgements}

Not applicable.

\section{Funding}

The present study was supported in part by grants from the Shandong Provincial Natural Science Foundation, China (grant no. ZR2010HM041) and the Shandong Provincial Postdoctoral Innovation Foundation, China (grant no. 201102004).

\section{Availability of data and materials}

The datasets used and/or analyzed during the current study are available from the corresponding author on reasonable request.

\section{Authors' contributions}

JY contributed to study design, to analysis and interpretation of the data, and to writing and revision of the manuscript. NW, YL and HZ performed the tests of serum iron and ferritin. FQ, XW and QZ prepared the blood samples and aided with the testing of serum iron and ferritin. FC and WL analyzed and interpreted the data, and revised the manuscript. All authors read and approved the final manuscript.

\section{Ethics approval and consent to participate}

The study protocol was approved by the Medical Ethics Committee of Linyi People's Hospital (Linyi, China). Each subject that agreed to enroll in the study reviewed and signed an informed consent form prior to their participation.

\section{Consent for publication}

Written informed consent obtained from all subjects permitted the publication of their data for research purposes following anonymization.

\section{Competing interests}

The authors declare that they have no competing interests.

\section{References}

1. Kiernan MC, Vucic S, Cheah BC, Turner MR, Eisen A, Hardiman O, Burrell JR and Zoing MC: Amyotrophic lateral sclerosis. Lancet 377: 942-955, 2011.

2. Hardiman O, van den Berg LH and Kiernan MC: Clinical diagnosis and management of amyotrophic lateral sclerosis. Nat Rev Neurol 7: 639-649, 2011. 
3. Logroscino G, Traynor BJ, Hardiman O, Chiò A, Mitchell D, Swingler RJ, Millul A, Benn E and Beghi E; EURALS: Incidence of amyotrophic lateral sclerosis in Europe. J Neurol Neurosurg Psychiatry 81: 385-390, 2010.

4. Couratier P, Corcia P, Lautrette G, Nicol M, Preux PM and Marin B: Epidemiology of amyotrophic lateral sclerosis: A review of literature. Rev Neurol (Paris) 172: 37-45, 2016.

5. Byrne S, Walsh C, Lynch C, Bede P, Elamin M, Kenna K, McLaughlin R and Hardiman O: Rate of familial amyotrophic lateral sclerosis: A systematic review and meta-analysis. J Neurol Neurosurg Psychiatry 82: 623-627, 2011.

6. Zarei S, Carr K, Reiley L, Diaz K, Guerra O, Altamirano PF, Pagani W, Lodin D, Orozco G and Chinea A: A comprehensive review of amyotrophic lateral sclerosis. Surg Neurol Int 6: 171, 2015.

7. Holecek V and Rokyta R: Possible etiology and treatment of amyotrophic lateral sclerosis. Neuro Endocrinol Lett 38: 528-531, 2018.

8. Redler RL and Dokholyan NV: The complex molecular biology of amyotrophic lateral sclerosis (ALS). Prog Mol Biol Trans Sci 107: 215-262, 2012.

9. Cookson MR and Shaw PJ: Oxidative stress and motor neurone disease. Brain Pathol 9: 165-186, 1999.

10. Kim K, Lee SG, Kegelman TP, Su ZZ, Das SK, Dash R, Dasgupta S, Barral PM, Hedvat M, Diaz P, et al: Role of excitatory amino acid transporter-2 (EAAT2) and glutamate in neurodegeneration: Opportunities for developing novel therapeutics. J Cell Physiol 226: 2484-2493, 2011.

11. Taylor JP, Hardy J and Fischbeck KH: Toxic proteins in neurodegenerative disease. Science 296: 1991-1995, 2002.

12. Rosen DR, Siddique T, Patterson D, Figlewicz DA, Sapp P, Hentati A, Donaldson D, Goto J, O'Regan JP, Deng HX, et al: Mutations in $\mathrm{Cu} / \mathrm{Zn}$ superoxide dismutase gene are associated with familial amyotrophic lateral sclerosis. Nature 362: 59-62, 1993.

13. Jeong SY, Rathore KI, Schulz K, Ponka P, Arosio P and David S: Dysregulation of iron homeostasis in the CNS contributes to disease progression in a mouse model of amyotrophic lateral sclerosis. J Neurosci 29: 610-619, 2009.

14. Oshiro S, Morioka MS and Kikuchi M: Dysregulation of iron metabolism in Alzheimer's disease, Parkinson's disease, and amyotrophic lateral sclerosis. Adv Pharmacol Sci 2011: 378278, 2011.

15. Hadzhieva M, Kirches E, Wilisch-Neumann A, Pachow D, Wallesch M, Schoenfeld P, Paege I, Vielhaber S, Petri S, Keilhoff G et al: Dysregulation of iron protein expression in the G93A mode of amyotrophic lateral sclerosis. Neuroscience 230: 94-101, 2013.

16. Chen P,Miah MR and Aschner M: Metals and Neurodegeneration. F1000Res: Mar 17, 2016. doi: 10.12688/f1000research.7431.1.

17. Veyrat-Durebex C, Corcia P, Mucha A, Benzimra S, Mallet C, Gendrot C, Moreau C, Devos D, Piver E, Pagès JC, et al: Iron metabolism disturbance in a French cohort of ALS patients. BioMed Res Int 2014: 485723, 2014

18. Kasarskis EJ, Tandon L, Lovell MA and Ehmann WD: Aluminum, calcium, and iron in the spinal cord of patients with sporadic amyotrophic lateral sclerosis using laser microprobe mass spectroscopy: A preliminary study. J Neurol Sci 130: 203-208, 1995.

19. Ince PG, Shaw PJ, Candy JM, Mantle D, Tandon L, Ehmann WD and Markesbery WR: Iron, selenium and glutathione peroxidase activity are elevated in sporadic motor neuron disease. Neurosci Lett 182: 87-90, 1994

20. Hozumi I, Hasegawa T, Honda A, Ozawa K, Hayashi Y, Hashimoto K, Yamada M, Koumura A, Sakurai T, Kimura A, et al: Patterns of levels of biological metals in CSF differ among neurodegenerative diseases. J Neurol Sci 303: 95-99, 2011.

21. Zheng Y, Gao L, Wang D and Zang D: Elevated levels of ferritin in the cerebrospinal fluid of amyotrophic lateral sclerosis patients. Acta Neurol Scand 136: 145-150, 2017.

22. Qureshi M, Brown RH Jr, Rogers JT and Cudkowicz ME: Serum ferritin and metal levels as risk factors for amyotrophic lateral sclerosis. Open Neurol J 2: 51-54, 2008.

23. Goodall EF, Haque MS and Morrison KE: Increased serum ferritin levels in amyotrophic lateral sclerosis (ALS) patients. J Neurol 255: 1652-1656, 2008.

24. Ikeda K, Hirayama T, Takazawa T, Kawabe K and Iwasaki Y: Relationships between disease progression and serum levels of lipid, urate, creatinine and ferritin in Japanese patients with amyotrophic lateral sclerosis: A cross-sectional study. Intern Med 51: 1501-1508, 2012

25. Nadjar Y, Gordon P, Corcia P, Bensimon G, Pieroni L, Meininger V and Salachas F: Elevated serum ferritin is associated with reduced survival in amyotrophic lateral sclerosis. PLoS One 7: e45034, 2012 .
26. Su XW, Clardy SL, Stephens HE, Simmons Z and Connor JR Serum ferritin is elevated in amyotrophic lateral sclerosis patients. Amyotroph Lateral Scler Frontotemporal Degener 16: 102-107, 2015.

27. Brooks BR: El Escorial World Federation of Neurology criteria for the diagnosis of amyotrophic lateral sclerosis. Subcommittee on Motor Neuron Diseases/Amyotrophic Lateral Sclerosis of the World Federation of Neurology Research Group on Neuromuscular Diseases and the El Escorial 'Clinical limits of amyotrophic lateral sclerosis' workshop contributors. J Neurol Sci 124: 96-107, 1994.

28. Kollewe K, Mauss U, Krampfl K, Petri S, Dengler R and Mohammadi B: ALSFRS-R score and its ratio: A useful predictor for ALS-progression. J Neurol Sci 275: 69-73, 2008.

29. Lechtzin N, Maragakis NJ, Kimball R, Busse A, Hoffman V and Clawson L: Accurate ALSFRS-R scores can be generated from retrospective review of clinic notes. Amyotroph Lateral Scler 10: 244-247, 2009

30. Contestabile A: Amyotrophic lateral sclerosis: From research to therapeutic attempts and therapeutic perspectives. Curr Med Chem 18: 5655-5665, 2011.

31. Jomova K, Vondrakova D, Lawson M and Valko M: Metals, oxidative stress and neurodegenerative disorders. Mol Cell Biochem 345: 91-104, 2010.

32. Boldt DH: New perspectives on iron: An introduction. Am J Med Sci 318: 207-212, 1999.

33. Qian ZM and Wang Q: Expression of iron transport proteins and excessive iron accumulation in the brain in neurodegenerative disorders. Brain Res Brain Res Rev 27: 257-267, 1998.

34. Rivera-Mancía S, Pérez-Neri I, Ríos C, Tristán-López L, Rivera-Espinosa L and Montes S: The transition metals copper and iron in neurodegenerative diseases. Chem Biol Interact 186: 184-199, 2010.

35. Casadesus G, Smith MA, Zhu X, Aliev G, Cash AD, Honda K, Petersen RB and Perry G: Alzheimer disease: Evidence for a central pathogenic role of iron-mediated reactive oxygen species. J Alzheimers Dis 6: 165-169, 2004

36. Castellani RJ, Moreira PI, Liu G, Dobson J, Perry G, Smith MA and Zhu X: Iron: The Redox-active center of oxidative stress in Alzheimer disease. Neurochem Res 32: 1640-1645, 2007.

37. Smith MA, Harris PL, Sayre LM and Perry G: Iron accumulation in Alzheimer disease is a source of redox-generated free radicals. Proc Natl Acad Sci USA 94: 9866-9868, 1997.

38. Olsen MK, Roberds SL, Ellerbrock BR, Fleck TJ, McKinley DK and Gurney ME: Disease mechanisms revealed by transcription profiling in SOD1-G93A transgenic mouse spinal cord. Ann Neurol 50: 730-740, 2001

39. Yu J, Guo Y, Sun M, Li B, Zhang Y and Li C: Iron is a potential key mediator of glutamate excitotoxicity in spinal cord motor neurons. Brain Res 1257: 102-107, 2009.

40. Langkammer C, Enzinger C, Quasthoff S, Grafenauer P, Soellinger M, Fazekas F and Ropele S: Mapping of iron deposition in conjunction with assessment of nerve fiber tract integrity in amyotrophic lateral sclerosis. J Magn Reson Imaging 31: 1339-1345, 2010

41. Mitchell RM, Simmons Z, Beard JL, Stephens HE and Connor JR Plasma biomarkers associated with ALS and their relationship to iron homeostasis. Muscle Nerve 42: 95-103, 2010.

42. Petri S, Körner S and Kiaei M: Nrf2/ARE signaling pathway: Key mediator in oxidative stress and potential therapeutic target in ALS. Neurol Res Int 2012: 878030, 2012.

43. Wang Q, Zhang X, Chen S, Zhang X, Zhang S, Youdium M and Le W: Prevention of motor neuron degeneration by novel iron chelators in SOD1(G93A) transgenic mice of amyotrophic lateral sclerosis. Neurodegener Dis 8: 310-321, 2011.

44. Golko-Perez S, Mandel S, Amit T, Kupershmidt L, Youdim MB and Weinreb O: Additive Neuroprotective effects of the multifunctional iron chelator M30 with enriched diet in a mouse model of amyotrophic lateral sclerosis. Neurotox Res 29: 208-217, 2016.

45. Greenwood DI: Nutrition management of amyotrophic lateral sclerosis. Nutr Clin Pract 28: 392-399, 2013.

46. Traynor BJ, Codd MB, Corr B, Forde C, Frost E and Hardiman OM: Clinical features of amyotrophic lateral sclerosis according to the El Escorial and Airlie House diagnostic criteria: A population-based study. Arch Neurol 57: 1171-1176, 2000.

47. Molfino A, Kushta I, Tommasi V, Rossi Fanelli F and Muscaritoli M: Amyotrophic lateral sclerosis, enteral nutrition and the risk of iron overload. J Neurol 256: 1015-1016, 2009.

48. Yu J, Qi F, Wang N, Gao P, Dai S, Lu Y, Su Q, Du Y and Che F: Increased iron level in motor cortex of amyotrophic lateral sclerosis patients: An in vivo MR study. Amyotroph Lateral Scler Frontotemporal Degener 15: 357-361, 2014. 